\title{
Mitochondrial DNA Phylogenetic Definition of a Group of 'Arid-Zone' Carduelini Finches
}

\author{
Antonio Arnaiz-Villena ${ }^{1, *}, J^{2}$ Mos Mososo ${ }^{1}$, Valentin Ruiz-del-Valle ${ }^{1}$, Javier Gonzalez ${ }^{2}$, Raquel \\ Reguera $^{1}$, Almudena Ferri ${ }^{1}$, Michael Wink ${ }^{2}$ and Juan Ignacio Serrano-Vela ${ }^{1}$
}

${ }^{I}$ Department of Immunology, University Complutense, The Madrid Regional Blood Center, Madrid, Spain and ${ }^{2}$ Institut
für Pharmazie und Molekulare Biotechnologie, Abteilung Biologie, Ruprecht-Karls-Universität Heidelberg, Heidelberg,
Germany

\begin{abstract}
Birds included within the Carduelini tribe (genera Rhodopechys, Carpodacus and Leucosticte) apparently belong to the same radiation according to molecular phylogenetic analyses. Our phylogenetic analyses based on nucleotide sequences of the cytochrome $b$ gene (cyt-b) indicate that some of these birds (Rhodopechys mongolica, $R$. githaginea and Carpodacus nipalensis) do not cluster together with their respective phenetically defined allies. This new group of birds thrives in both hot and cold arid zones and are phenetically distinct, probably because of their adaptation to different extreme environments. Both maximum likelihood and Bayesian inference methods support the existence of this new evolutionary basal group among finches which might have originated about 14 million years ago.
\end{abstract}

Key Words: Carduelini, Carpodacus, finch, Fringillinae, Leucosticte, phylogeny, Rhodopechys, rosefinches.

\section{INTRODUCTION}

The evolutionary histories of songbirds (class Aves, order Passeriformes, suborder Passeri) have been broadly studied. Their phenotypic, behavioural and molecular evolution are not always concordant $[1,2]$. Thus, the parallelism in morphology and behavioural characters may lead to shared features among non-closely genetically related species occurring in similar or quasi-identical environments, and conversely, distinct features may occur among genetic sister taxa thriving under different environments. Evidence of this phenotypic plasticity has already been documented for other bird species [3-7]. Therefore, some genetic and/or phenetic traits apparently may not correlate with the evolutionary histories of the birds under study.

Mitochondrial cytochrome $b$ gene (cyt-b) sequencing has been widely used in molecular systematics. This gene has been proved to be helpful for defining evolutionary relationships among relatively distant or closely related taxa, even at the subspecies level [8-10].

Here, we study some passerine species that belong to the genera Rhodopechys, Carpodacus and Leucosticte which do not cluster together with their corresponding genera according to molecular phylogenetic studies $[1,11,12]$. These songbirds belong to the tribe Carduelini (family Fringillidae, subfamily Fringillinae) and thrive in extreme environments, either in deserts (Rhodopechys) or high altitude habitats (Carpodacus and Leucosticte). Birds from the genus Rhodopechys inhabit deserts or very arid areas of Africa and Central Asia and have pale or sandy coloured wings and bills [13]. Four species are included within this genus: $R$. githa-

\footnotetext{
*Address correspondence to this author at the Departamento de Inmunologia, Facultad de Medicina, Universidad Complutense de Madrid, Avenida Complutense s/n, 28040 Madrid, Spain; Tel: +34913017354; Fax: +34913017213; E-mail: aarnaiz@med.ucm.es; http://chopo.pntic.mec.es/biolmol
}

ginea (trumpeter finch), R. mongolica (Mongolian finch), $R$. obsoleta (desert finch) and $R$. sanguineus (crimson-winged finch). The desert finch has recently been reported not to be genetically close to Rhodopechys species, but to be an ancestor of greenfinches from the genus Carduelis [12]. The rosefinches (genus Carpodacus) are high-altitude birds that have probably originated in the Himalayas [13]. Only one species (out of 21), the common rosefinch (Carpodacus erythrinus), has a Palearctic distribution and breeds at low altitudes. All the species of the genus Carpodacus are distributed in Asia (including Middle East), except C. mexicanus (house finch), C. cassinii (Cassin's finch) and C. purpureus (purple finch) which thrive in North America. The dark-breasted rosefinch (Carpodacus nipalensis) does not phylogenetically cluster with either American or Asian Carpodacus [11, 14]. The genus Leucosticte comprises three species: L. nemoricola (plain mountain finch), L. brandti (black-headed mountain finch) and L. arctoa (rosy finch). They are dark-plumaged sparrow-like birds that thrive in high altitude habitats of Central Asia and, in the case of Leucosticte arctoa, also in western North America. Some authors separate the rosy finch into two (or even three) different species (or subspecies) depending on the distribution range [13]. Here, we consider one species with two subspecies: the Asian rosy finch (L. arctoa arctoa) and the American rosy finch (L. a. tephrocotis).

In the present work we analyze the genetic relatedness among tribe Carduelini species using mt cyt-b DNA sequences previously obtained by us [11,12, 15-17], including the only Leucosticte cyt-b DNA sequence available so far $(L$. arctoa tephrocotis, AY156385) and a new one obtained by us for this study (L. arctoa arctoa, DQ257460). Our work has also been enhanced because we previously had preliminary results suggesting that a small group of 'arid-zone' finches (species from genera Carpodacus, Rhodopechys and Leucosticte) might be defined. 


\section{MATERIALS AND METHODOLOGY}

\section{Bird Samples, DNA Extraction and PCR Amplifications}

Sixty one species of songbirds (order Passeriformes, suborder Passeri) have been included in this study (see Table 1). They belong to the tribe Carduelini (family Fringillidae, subfamily Fringillinae). The species highlighted in grey were sequenced and analyzed in this study together with relevant species of the tribe Carduelini. Other sequences included in this analysis were retrieved from the GenBank (see Table 1) [11, 12, 15-17].

DNA was obtained from blood taken by cutting one claw after anesthetizing with a lidocaine ointment. Blood was collected in EDTA and frozen until use. DNA extraction was performed using a standard phenol-chloroform protocol [18]. Amplification and sequencing of 924 base pairs (bp) of the cyt-b gene was carried out as previously described by Zamora et al. [12]. Nuclear mitochondrial insertions ("numts") were not detected, since their evolutionary rate is different and they usually have stop codons. Our phylogeny methodologies would have detected these different evolutionary rates by leaving "numts" as outliers.

\section{Phylogenetic Analyses}

The sequences were aligned and checked for stop codons with MEGA v. 3.1 [19]. The phylogenetic dendrograms were reconstructed using maximum likelihood (ML) [20] in PAUP* v. 4.0b10 [21] and Bayesian inference (BI) [22] in MrBayes v. 3.1.2 [23]. Modeltest v. 3.7 [24] was employed to find the model of DNA substitution that fits the data best. The best model was then used in both the ML and BI analyses. The linearized ML dendrograms were calculated with PAUP* v. 4.0b10 [21] with the branch lengths estimated according to the model proposed by Thorne et al. [25] which assumes that the rates among the evolutionary lineages may not be constant. The tree reconstruction strategy consisted of a heuristic search with NNI (Nearing-Neighbour Interchange) swapping algorithm. Robustness of nodes was assessed by 1000 bootstrap replicates in the ML analyses. The rates of the parameters defining the model of evolution were allowed to change in the BI analysis after each generation in order to increase the likelihood of the resulting trees. Thus, none of the parameters were fixed a priori. In BI analyses, two independent runs (with one cold and three heated chains each) were performed along with 5 million generations. Trees were sampled every 100 generations and the first 12,500 samples were discarded as 'burn-in'. The average standard deviation of split frequencies approached to zero being around 0.01 at the end of the analysis. The posterior probability values (ppv) indicate the robustness of the nodes in the BI. In our phylogenetic analyses the lark-like bunting, Emberiza impetuani (family Fringillidae, subfamily Emberizinae, tribe Emberizini), was used as an outgroup (see Table 1).

\section{RESULTS}

The phylogenetic analyses using ML and BI methods converged on a congruent topology (Figs. 1, 2). In general, we found several monophyletic clades, namely, crossbills (genus Loxia; ML bootstrap=100, BI ppv=1.00) and bullfinches (genus Pyrrhula; ML bootstrap=83, BI ppv=1.00).
Rosefinches (genus Carpodacus) form a polyphyletic clade, as it was already shown by Arnaiz-Villena et al. [11]. The species of the genera Carduelis and Serinus, however, are clustered in several paraphyletic groups as described in a previous study [17]. On the other hand, some monotypic genera group with another different genus: Pinicola enucleator (pine grosbeak) forms a clade with genus Pyrrhula (ML bootstrap $=81$, BI ppv=0.91), Uragus sibiricus (long-tailed rosefinch) goes with Carpodacus rubicilloides (ML bootstrap $=30, \mathrm{BI}$ ppv=0.92) and Haematospiza sipahi (scarlet finch) is clustered together with Carpodacus erythrinus (ML bootstrap $=49$, BI ppv=0.97); this is concordant with previous results [11]. Also, Rhodopechys obsoleta is grouped with the greenfinches (Carduelis), spliting genus Rhodopechys, as expected [12]. Citril finch (Serinus citrinella) groups with the European goldfinch (Carduelis carduelis), which is congruent with previous findings $[17,26]$. Finally, a phylogenetic group consistently contained two species of the genus Rhodopechys (R. mongolica and $R$. githaginea), two subspecies of Leucosticte arctoa (L. a. arcota and L. a. tephrocotis) and the dark-breasted rosefinch (Carpodacus nipalensis). This group is supported by a bootstrap value of 60 in the ML tree (Fig. 1) and a posterior probability value of 1.00 in the Bayesian tree (Fig. 2). This new group might represent a Carduelini group of 'arid-zone' birds. Note that Rhodopehcys sanguineus, Leucosticte brandti, and Leucosticte nemoricola may probably belong to this group. Samples and further analyzes are necessary to assess this hypothesis.

Considering the maximum likelihood genetic divergences and the corresponding cladogenesis timing among the taxa analysed (see Fig. 1 footnote), the genera Carduelis and Serinus diverged recently and simultaneously. Moreover, rosefinches diverged earlier; and the bullfinches (Pyrrhula) as well as the 'arid-zone' finches diverged even earlier at the base of the tree (Fig. 1).

\section{DISCUSSION}

\section{Phylogenetic Relationships}

Our aim in the present work was to find the phylogenetic position of some Carduelini species that have been left out from 'their own' predicted genera in previous analyses, e.g. Rhodopechys mogolica, Rhodopechys githaginea and Carpodacus nipalensis $[11,12]$, and to test whether they group together with other 'extreme environment' Carduelini finches like Leucosticte species. The new 'arid-zone' group was supported by both ML and BI analyses (Figs. 1, 2) (the same results were found with neighbor-joining and maximum parsimony analyses, data not shown). Our results, particularly the Bayesian analysis (Fig. 2), confirm previous phylogenetic finding on the tribe Carduelini [11, 15-17]. These phylogenetic analyses had not been done under Bayesian premises until now.

\section{Biogeographical and Evolutionary Pattern Hypotheses}

The ML tree was linearized in order to obtain a rough estimate of phylogenetic divergences and the age of different lineages among Carduelini. A molecular clock model was applied to the cytochrome $b$ gene using two different estimations of divergence time: one based on galliform birds [11, $15,16]$ and another based on Hawaiian honeycreepers [12, 
Table 1. Origin of Samples and Cytochrome b GenBank Accession Numbers of the Species Analyzed in this Study

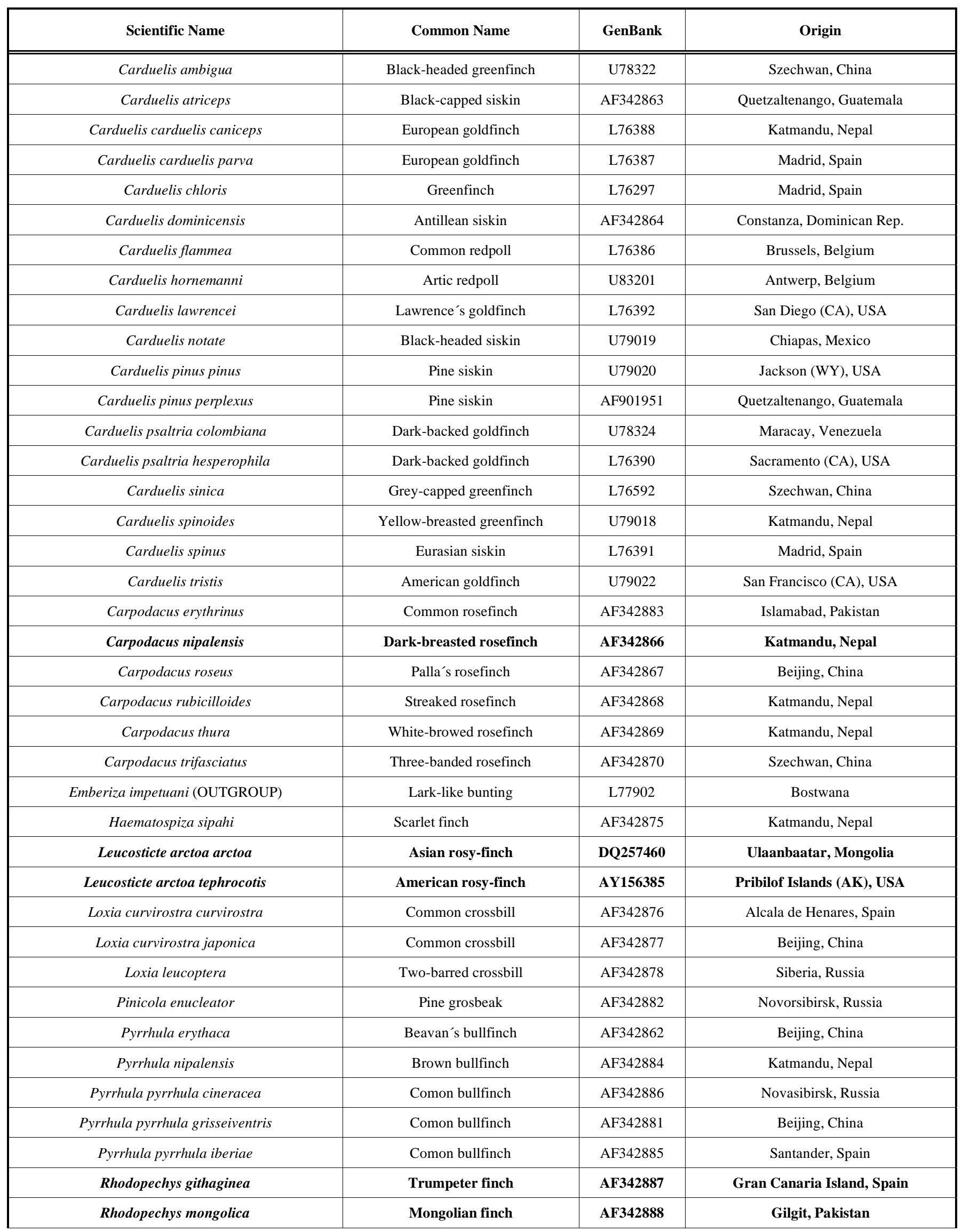


(Table 1) contd....

\begin{tabular}{|c|c|c|c|}
\hline Rhodopechys obsoleta & Desert finch & AF342889 & Kabul, Afghanistan \\
\hline Serinus albogularis & Whited-throated canary & L78705 & Capetown, South Africa \\
\hline Serinus atrogularis & Yellow-rumped seedeater & L76267 & Capetown, South Africa \\
\hline Serinus canicollis & Yellow-crowned canary & L78706 & Capetown, South Africa \\
\hline Serinus citrinella citrinella & Citril finch & L77872 & Madrid, Spain \\
\hline Serinus citrinella corsicanus & Citril finch & AY583725 & Sardinia, Italy \\
\hline Serinus citrinelloides & African citril & L77555 & Nairobi, Kenya \\
\hline Serinus flaviventris & Yellow canary & L76280 & Capetown, South Africa \\
\hline Serinus gularis & Streaky-headed seedeater & L77556 & Capetown, South Africa \\
\hline Serinus leucopygius & White-rumped seedeater & L76264 & Dakar, Senegal \\
\hline Serinus mozambicus & Yellow-fronted canary & L76265 & Dar es Salam, Tanzania \\
\hline Serinus pusillus & Red-fronted serin & L77873 & Sin Wiang, China \\
\hline Serinus serinus & European serin & L76263 & Madrid, Spain \\
\hline Serinus striolatus & Streaky seedeater & L77557 & Nairobi, Kenya \\
\hline Serinus sulphuratus & Brimstone canary & L76294 & Capetown, South Africa \\
\hline
\end{tabular}

The 'Arid-Zone' Finches are in Bold

17]. Both estimations of divergence timing did not exhibit significant differences, but they are only approximations.

The Miocene Epoch is characterized by an initial cold peak (Mi-1) followed by a general Earth warming; the tundra was replaced by conifer woods in the corresponding areas between 17 and 14.5 million years ago (MYA) [27] when the temperatures were $6^{\circ} \mathrm{C}$ higher than at present times [27]. However, after 14.5 MYA the temperatures started to drop and finally the Antarctica and Greenland became glaciated around 6 MYA. Simultaneously with this general cooling, vast arid regions appeared in Asia and Africa [27]. In addition, the Tibet plateau underwent its most important uplift during this cold Miocene period [27, 28]. The heavy rain regime in the high Tibet-Himalayan peaks gave rise to the birth of deep and plentiful rivers (Ganges, Bramaputra, Yangtze and Mekong) which carry 25\% of the total suspension materials that reach the oceans on Earth.

The ancestors of the new group of 'arid-zone' Carduelini might have appeared 13.5 MYA. This is roughly coincidental with the appearance of vast arid areas in Africa and Asia. This radiation might have started around this time in Asia (or less likely in Africa) from where some of the lineages later might have undergone dispersal during warmer conditions.
This may be the case of Leucosticte arctoa now thriving both in Asia and America.

The 'arid-zone' finches' plumage colours are not homogeneous and some Leucosticte and Carpodacus finches bear more melanine pigment. This may suggest a more recent and disparate change in the 'arid-zone' finches' environments. More humid habitats (i.e., those of Leucosticte and Carpodacus nipalensis in comparison with Rhodopechys habitats) favour melanine dyed feathers, because it protects plumage from bacterial degradation by humidity [29]. Carotenoids, the other major pigments responsible for plumage colouration [30], are scarce in dry areas, but Carpodacus nipalensis also feeds on berries at high altitudes [13] and this may cause the intense male purple face colouring at breeding. Also, $C$. nipalensis has the darkest plumage colours among rosefinches [13], resembling Leucostice finches in this respect.

In summary, according to our phylogenetic analyses based on mitochondrial cytochrome b DNA sequences, the genera Rhodopechys and Carpodacus should be revised because this 'arid-zone' separate evolutionary group comprises species belonging to both of the genera. Further analyses using nuclear markers could be required to complete the 


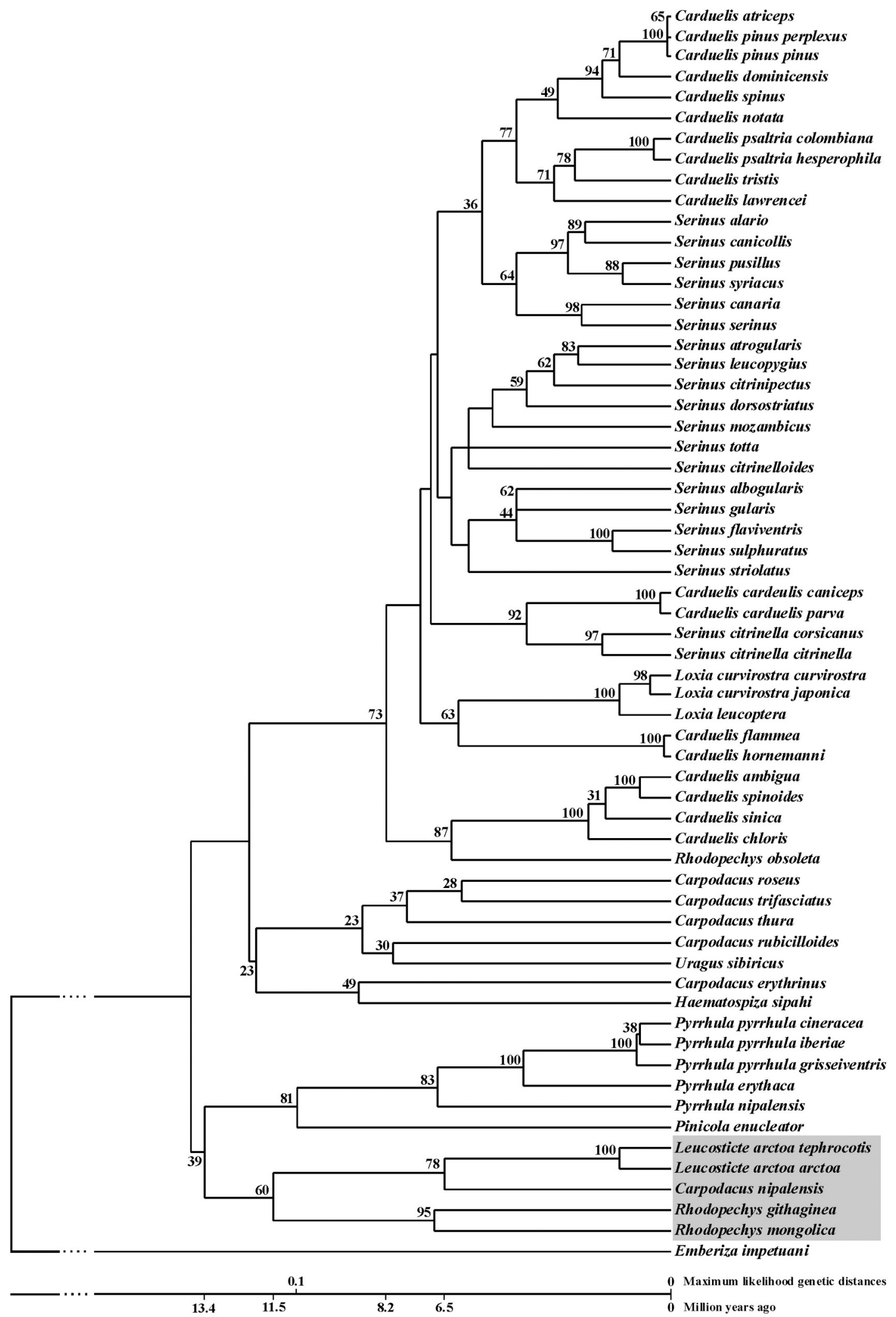

Fig. (1). Maximum likelihood (ML) linearized tree based on 924 bp mitochondrial cytochrome $b$ DNA sequences (ln $L=8612.08$ ). The general time reversible model GTR $+\mathrm{I}=0.5788+\mathrm{G}=1.2061$ was used as a priori settings in the analysis (base frequencies: A=0.29280, $\mathrm{C}=0.41180, \mathrm{G}=0.13990, \mathrm{~T}=0.15550$; rates of nucleotide substitution: $\mathrm{AC}=0.848200, \mathrm{AG}=6.167300, \mathrm{AT}=2.208400, \mathrm{CG}=0.175600$, $\mathrm{CT}=21.150900, \mathrm{GT}=1.0000$ ). Thorne's model [25] was used to estimate branch lengths. Bootstrap values are indicated for each node. The time scale indicates approximate the divergence times according to previous results $[11,15,16,31]$. 'Arid-zone' finches are highlighted in grey. 


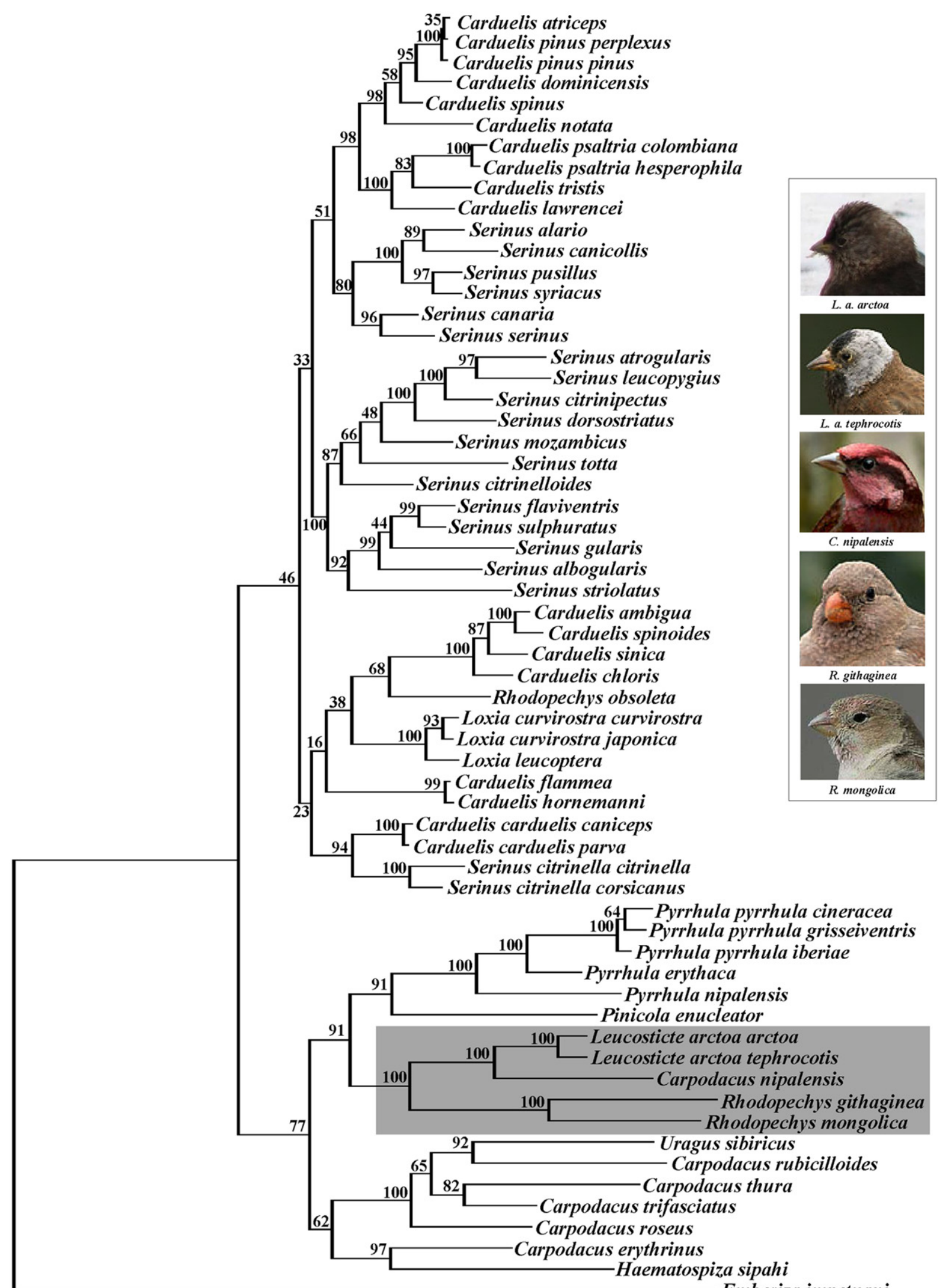

Emberiza impetuani

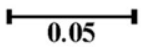

Fig. (2). Bayesian phylogenetic tree based on 924 bp of the mitochondrial cytochrome $b$ DNA sequences. The model of evolution used was GTR + I + G. 5,000,000 generations were run, the sampling of the trees every 100 generations and the first 12,500 samples were discarded as 'burn-in'. The posterior probability values (x100) are indicated for each node. 'Arid-zone' finches are highlighted in grey along with their corresponding photographs. 
phylogenetic findings presented in this work, and a taxonomical revision of these genera is needed since only monophyletic clades should be used in a biological systematics, not only with the species studied here $[1,11]$.

\section{CONCLUSIONS}

A long lasting microgeographical study of Fringillinae birds by using mitochondrial DNA phylogenies has allowed defining a group of monophyletic Carpodacus/Rhodopechys/ Leucostice Carduelini birds, all of which thrive in arid areas. This 'arid-zone' group is clearly separated from other Carduelini radiations according to maximum likelihood and Bayesian methodologies.

\section{ACKNOWLEDGEMENTS}

We are grateful to Fundacion Mutua Madrileña Automovilista (2004, 2005, 2006 grants) and Ministerio de Sanidad (FIS, PI-051039) for their grants. All the experiments performed in the present work comply with the current Spanish laws. T.C.H. Cole made valuable comments to improve this manuscript.

\section{ABBREVIATIONS}

$\begin{array}{ll}\mathrm{BI} & =\text { Bayesian inference } \\ \mathrm{bp} & =\text { Base pairs } \\ \text { cyt-b } & =\text { Cytochrome } \mathrm{b} \\ \mathrm{ML} & =\text { Maximum likelihood } \\ \text { MYA } & =\text { Million years ago } \\ \text { ppv } & =\text { Posterior probability value }\end{array}$

\section{REFERENCES}

[1] Sibley CG, Ahlquist J. Phylogeny and classification of birds. New Heaven:Yale University Press; 1990.

[2] Pasquet E, Thibault JC. Genetic differences among mainland and insular forms of the citril finch Serinus citrinella. Ibis 1997; 139: 679-84.

[3] Marchetti K. Dark habitats and bright birds illustrate the role of the environment in species divergence. Nature 1993; 362: 149-52.

[4] Kusmierski R, Borgia G, Uy A, Grozier RH. Labile evolution of display traits in bowerbirds indicates reduced effects fo phylogenetic constraint. Proc R Soc Lond B-Biol Sci. 1997; 264: 307-13.

[5] McCracken K, Harshman J, McClellan D, Afton A. Data set incongruence and correlated character evolution: an example of functional convergence in the hind-limbs of stifftail diving ducks. Syst Biol. 1999; 48: 683-714

[6] van Tuinen M, Butvill DB, Kirsch JAW, Hedges SB. Convergence and divergence in the evolution of aquatic birds. Proc R Soc Lond B-Biol Sci. 2001; 268: 1345-50.

[7] Haavi J, Borge T, Bures S, et al. Flycatcher song in allopatry and sympatry - convergence, divergence and reinforcement. J Evol Biol. 2004; 17: 227-37.

[8] Wink M. Phylogeny of Old and New World vultures (Aves: Accipitridae and Cathartidae) inferred from nucleotide sequences of the mitochondrial cytochrome $b$ gene. Z Naturforsch. 1995; 50: 868-82.
[26] Arnaiz-Villena A, Ruiz-del-Valle V, Moscoso J, Serrano-Vela JI, Zamora J. mtDNA phylogeny of North American Carduelis pinus group. Ardeola 2007; 54: 8-14.

[27] Uriarte-Cantolla A. Historia del clima de la tierra. Vitoria:Servicio Central de Publicaciones del Gobierno Vasco; 2003.

[28] Chung SL, Lo CH, Zhang Y, et al. Diachronous uplift of the Tibetan plateau starting 40 Myr ago. Nature 1998; 394: 769-73.

[29] Burtt EHJ, Ichida JM. Gloger's rule, feather-degrading bacteria, and color variation among song sparrows. Condor 2004; 106: 681-86.

[30] Gill FB. Ornithology. New York:WH Freeman \& Co; 2006.

[31] Fleischer RC, McIntosh C, Tarr CL. Evolution on a volcanic conveyor belt: using phylogeographic reconstructions and K-A-based ages of the Hawaiian Islands to estimate molecular evolutionary rates. Mol Ecol. 1998; 7: 533-45. 